\title{
A New Window for the Treatment of Posterior Cerebral Artery, Superior Cerebellar Artery, and Basilar Apex Aneurysm: The Expanded Endoscopic Endonasal Approach
}

\author{
Ana M. Lemos-Rodríguez ${ }^{1}$ Satyan Sreenath ${ }^{1}$ \\ Adam Zanation ${ }^{1,2}$ Deanna Sasaki-Adams ${ }^{1,2}$ \\ ${ }^{1}$ Department of Otolaryngology, Head and Neck Surgery, University of \\ North Carolina at Chapel Hill, Chapel Hill, North Carolina, \\ United States \\ ${ }^{2}$ Department of Neurosurgery, University of North Carolina at Chapel \\ Hill, Chapel Hill, North Carolina, United States \\ 3 Brain Tumor and Neuro-Oncology Center, Cleveland Clinic, Cleveland, \\ Ohio, United States
}

Ajay Unnithan ${ }^{2}$ Vivian Doan ${ }^{2}$ Pablo F. Recinos ${ }^{3}$

J Neurol Surg B 2016;77:308-313.

\begin{abstract}
Address for correspondence Deanna Sasaki-Adams, MD, Department of Neurosurgery, University of North Carolina at Chapel Hill, 170 Manning Drive, CB \#7060, Chapel Hill, NC, 27599, United States (e-mail: deanna_sasaki-adams@med.unc.edu).
\end{abstract}

\begin{abstract}
Keywords

- endoscopic endonasal approach

- clipping aneurysms

- posterior cerebral artery aneurysms

- basilar apex aneurysm

- superior cerebellar aneurysm

Objective To explore the feasibility of an endoscopic endonasal transclival approach to treat aneurysms arising in the basilar apex, posterior cerebral arteries, and superior cerebellar arteries.

Study Design Cadaveric anatomical study.

Participants Fifteen cadaveric specimens.

Main Outcome Measures Degree of surgical exposure of each artery attained, distance from the nasal vestibule to these three arteries, and feasibility of clipping these vessels using standard vascular clip applicators.

Results Both posterior cerebral arteries were exposed, $0.67 \mathrm{~cm}$ (standard deviation [SD]: 0.2 ) on the right side and $0.59 \mathrm{~cm}$ (SD: 0.2) on the left side. Both right and left superior cerebral arteries were exposed, $0.6 \mathrm{~cm}$ (SD: 0.2 ) and $0.7 \mathrm{~cm}$ (SD: 0.3), respectively. The length of the basilar artery exposed was $2.6 \mathrm{~cm}$ (SD: 0.3 ). The distance from the nasal vestibule to the posterior cerebral artery, superior cerebellar artery, and basilar apex was $10 \mathrm{~cm}$ with an SD of $\pm 0.7,0.6$, and $0.8 \mathrm{~cm}$, respectively. We were able to apply clips on each of these three vessels with a minimal alteration of surrounding normal tissue.

Conclusion The endoscopic endonasal transclival approach represents a potentially feasible surgical corridor to treat aneurysms arising from these vessels.
\end{abstract}

\section{Introduction}

Since the initiation of endoscopic skull base surgery, this innovative technique has evolved over time. Initially, endoscopic skull base surgery was restricted to the approach of the pituitary fossa, but with the advent of new technology,

received

March 13, 2015

accepted

September 16, 2015

published online

December 2, 2015

neuronavigation systems, and improved anatomical understanding, we are now able to reach areas that were previously not amenable to treatment through an endonasal technique. From the cribriform plate down to the odontoid process of $\mathrm{C} 2$, the expanded endoscopic approach has given us great exposure and visualization of all the structures within this area

(c) 2016 Georg Thieme Verlag KG Stuttgart · New York
DOI http://dx.doi.org/ 10.1055/s-0035-1566252. ISSN 2193-6331. 
while avoiding brain retraction and manipulation of some neurovascular structures. The structures that we can access and visualize with this approach are the basilar apex (BA), superior cerebellar artery, and posterior cerebral artery.

Additionally, new reconstruction techniques have been developed to avoid postoperative complications such as cerebrospinal fluid (CSF) leakage. For many years this condition was rated as the major disadvantage of endoscopic endonasal approaches. The new techniques include vascularized nasoseptal flaps and secondary flaps. Studies reported a successful reconstruction rate of CSF leakage with the nasoseptal flap of $>94 \%^{1}$ in patients with high-flow defects. Secondary flaps also showed excellent results with a successful reconstruction rate of $97 \%$ comparable with the results of the nasoseptal flap alone. ${ }^{2}$ This surgical corridor and new options of reconstruction after surgery make the expanded endonasal approach an excellent option to treat pathologies in the midline skull base potentially including the BA, posterior cerebral artery, and superior cerebellar artery aneurysms. We present an anatomical study exploring the feasibility of an endoscopic endonasal transclival approach to treat aneurysms arising in these three main vessels.

\section{Methods}

Fifteen latex-injected adult cadaver heads were dissected using the endoscopic endonasal transclival approach. Endoscopic dissections were performed at the North Carolina Eye Bank Multidisciplinary Surgical Skills Laboratory at the University of North Carolina at Chapel Hill. A rigid endoscope $4 \mathrm{~mm}$ in diameter, $18 \mathrm{~cm}$ in length, with 0-degree lenses (Karl Storz Endoscopy, Tuttlingen, Germany) connected to a light source was used. We were able to take pictures and videos during the entire procedure.

We first performed a standard endoscopic endonasal transsphenoidal approach to the sellar region. Once the sphenoid cavity was completely exposed, the basopharyngeal fascia was removed completely from the floor of the sphenoid and the clival face. Drilling of the sphenoid floor was achieved until it was flush with the clivus, allowing the union of its sphenoidal and rhinopharyngeal portions. The clivus was removed completely; the eustachian tubes marked the lateral limits. The underlying dura mater was exposed and opened. Posteriorly, with a $10-\mathrm{cm}$ flexible surgical ruler (Kendall, Covidien, Mansfield, Massachusetts, United States), we measured the distance from the nasal vestibule to the BA, posterior cerebral artery, and superior cerebellar artery as well as the length exposed of each of them. Finally, using standard aneurysm clips (Aesculap AG, Tuttlingen, Germany) and clip appliers (Karl Storz, Tuttlingen, Germany), we clipped these three vessels in different portions of the length exposed.

\section{Results}

With the method just described we were able to expose the basilar artery in all of its extension, focusing primarily on the BA, the posterior cerebral artery segments $\mathrm{p} 1$ and $\mathrm{p} 2$, and the superior cerebellar artery ( - Fig. $\mathbf{1}$ ). The average

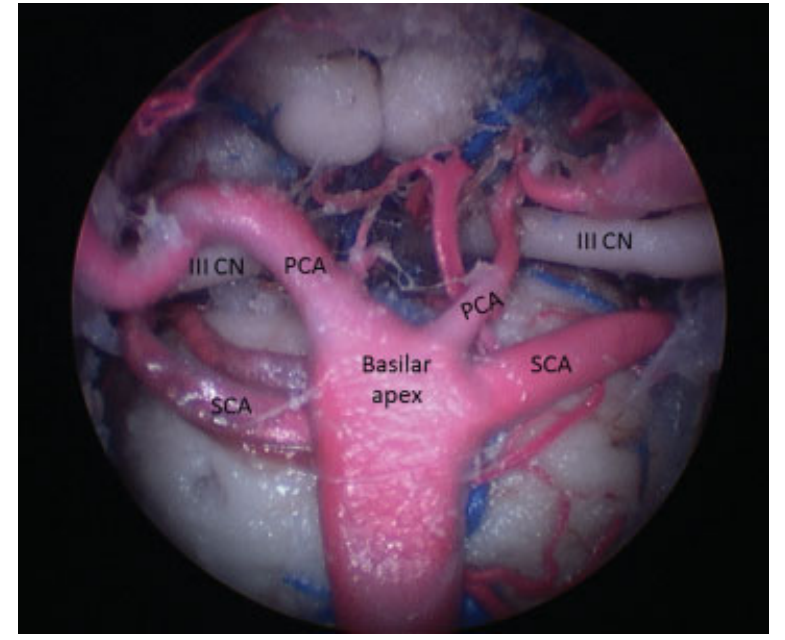

Fig. 1 Endoscopic view obtained in a cadaver showing basilar apex. CN, cranial nerve III; PCA, posterior cerebral arteries; SCA, superior cerebellar arteries.

length for the posterior cerebral artery exposed was $0.67 \pm 0.2 \mathrm{~cm}$ on the right side and $0.59 \pm 0.2 \mathrm{~cm}$ on the left side. Both right and left superior cerebellar arteries were exposed with an average length of $0.6 \pm 0.2 \mathrm{~cm}$ and $0.7 \pm 0.3 \mathrm{~cm}$, respectively. We identified cranial nerve $(\mathrm{CN})$ III running between the posterior cerebral and superior cerebellar arteries in all specimens, and we were able to avoid manipulation of this nerve when applying the clips. The length of the basilar artery exposed was $2.6 \pm 0.3 \mathrm{~cm}$ on average. The distance from the nasal vestibule to the posterior cerebral artery, superior cerebellar artery, and BA was $\sim 10 \mathrm{~cm}$ with an SD of $\pm 0.7,0.6$, and $0.8 \mathrm{~cm}$, respectively. We were able to place clips in the posterior cerebral artery, superior cerebellar artery, and BA using the standard clip applicators in different portions of the length exposed in each artery with minimal alteration of surrounding normal tissue in all the specimens (-Figs. 2 and 3 ; - Video 1 ).

\section{Video 1}

Endoscopic video showing the technique used to clip the posterior cerebellar artery and basilar artery.

Online content including video sequence is available at: https://www.thieme-connect.com/products/ ejournals/html/10.1055/s-0035-1566252

\section{Discussion and Literature Review}

BA aneurysms are the most commonly reported in the posterior cerebral arterial circulation, accounting for 50\%,4 of all posterior circulation aneurysms. BA aneurysms are associated with higher risk of bleeding, mortality, and morbidity compared with those seen in other posterior circulation locations. ${ }^{4}$ 


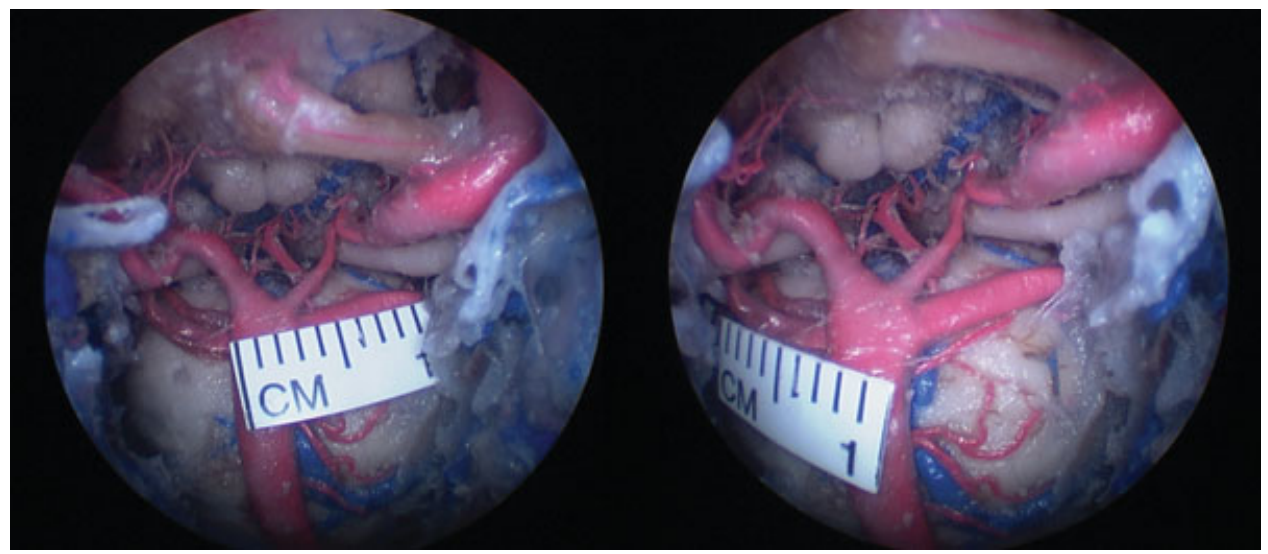

Fig. 2 Endoscopic view obtained in a cadaver showing the technique used to measure the basilar apex, superior cerebellar artery, and posterior cerebral artery. Measurement of the superior cerebellar artery is shown.

Different variations of the anatomy of BA aneurysms have been described. Nanda et $\mathrm{l}^{5}$ designated and reported in his clinical series the complex anatomy of a BA aneurysm in which criteria included an aneurysm $>10 \mathrm{~cm}$, calcified or thrombosed, neck $\geq 4 \mathrm{~mm}$ (up to $60 \%$ of all BA aneurysms), ${ }^{4}$ posterior direction, and retro/subsellar aneurysms. Aneurysms that did not have these criteria were considered simple aneurysms. In addition to the posterior projection, the anterior projection, toward the dorsum sellae, and the upward projection, toward the posterior diencephalon, have also been described. ${ }^{3,6} \mathrm{~A}$ great proportion of BA aneurysms are associated with posterior cerebral and superior cerebellar aneurysms. The sum of all of these features makes this pathology one of the most difficult to treat with surgery and endovascular interventions.

Posterior cerebral artery aneurysms have a lower incidence of occurrence compared with BA aneurysms. They represent only $1 \%$ of all intracranial aneurysms. ${ }^{7}$ Due to the many perforating branches that originate in the posterior cerebral artery, and the different anatomical territories that it supplies, an excellent knowledge of the posterior cerebral artery anatomy is necessary. P1 and P2 segments of the

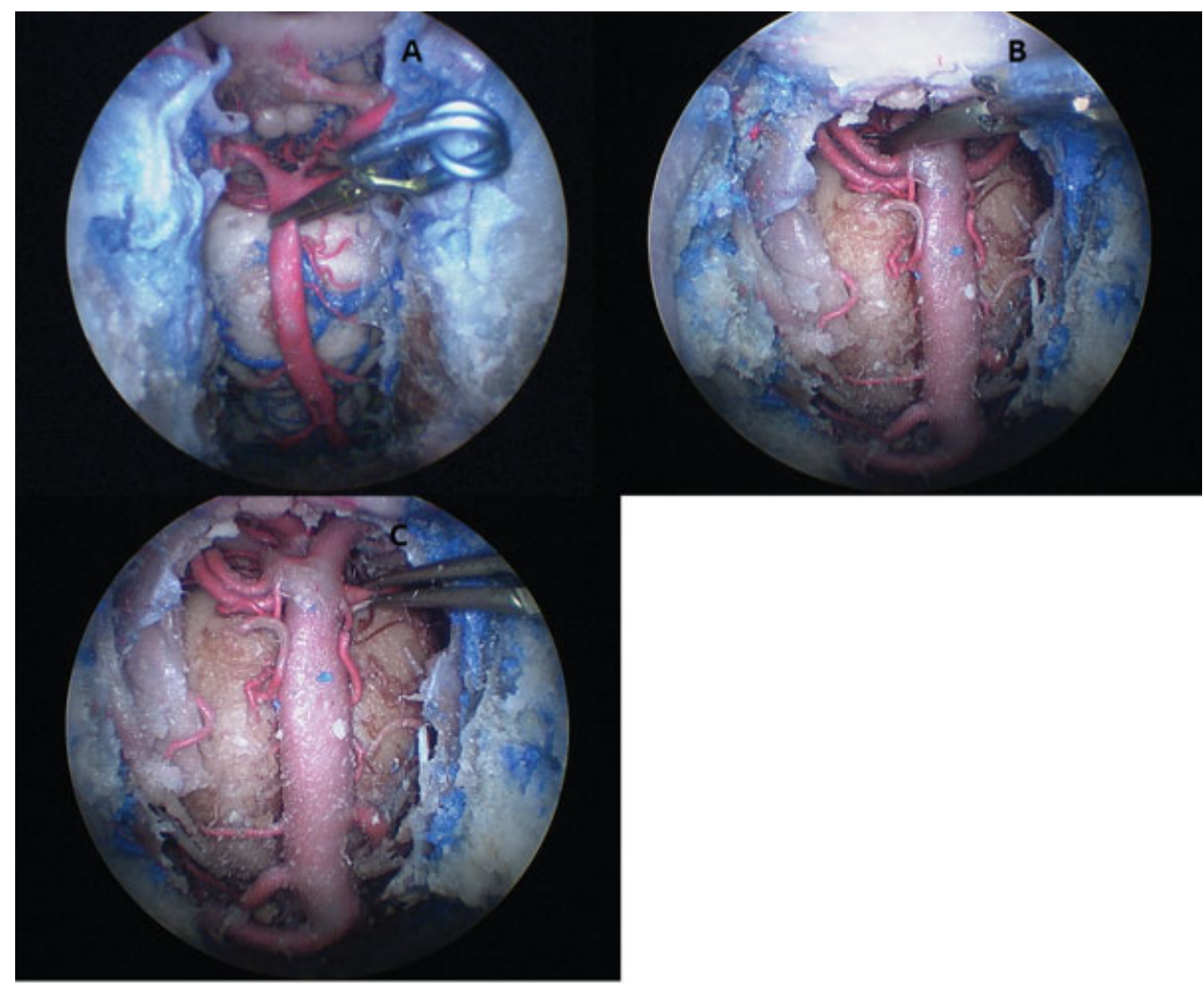

Fig. 3 Endoscopic view showing clip placement. (A) Basilar artery. (B) Posterior cerebral artery. (C) Superior cerebellar artery. 
posterior cerebral artery are the locations most often reported in the literature ${ }^{7-10}$ that we were able to expose with the endonasal endoscopic approach. In patients without an antecedent of a subarachnoid hemorrhage, having an aneurysm located in the posterior cerebral artery represents an independent higher risk of rupture, as reported in the study of unruptured intracranial aneurysms in $1998 .^{11}$ These features increase the risk of morbidity and mortality related to this pathology.

Superior cerebellar artery aneurysms are rare. Few clinical series have been reported. ${ }^{12,13}$ They arise mainly at the origin of the superior cerebral artery from the basilar artery or between the origin of the superior cerebral and posterior cerebral arteries. $^{4,13}$ Compared with BA and posterior cerebral aneurysms, the size of superior cerebellar artery aneurysms are smaller, and they often present with a narrow neck. Additionally, inclusion of the artery origin into the aneurysm has been seen. No other morphological features have been described.

Different surgical approaches and endovascular interventions have been used and reported for the management of these aneurysms. The most common approaches used to reach the BA, superior cerebellar artery, and posterior cerebral artery have been the subtemporal approach and the pterional approach. The view of the aneurysm neck is perpendicular and shorter with the subtemporal approach; also there is no need to retract the great vessels, but there is a need to manipulate the third cranial nerve and temporal lobe. ${ }^{3,5,14}$ The pterional approach widens the distance between the internal carotid artery and the third cranial nerve that avoids manipulation of the latter, but the oblique direction of the approach affects the visibility of the vessels in question, and it is associated with a longer working distance and the manipulation of the posterior clinoid process. Other approaches has been used less frequently: the transcavernous approach with posterior clinoidectomy, middle fossa approach with medial petrosectomy, orbitozygomatic craniotomy, and transsylvian approach, ${ }^{15}$ all of them trying to increase the range of visibility, improve the ability of sharp dissection, avoid damage of the perforating vessels, and decrease manipulation of CN III. None of these approaches sufficiently negates the associated risks of the procedure. Additionally all the approaches just described involve significant brain retraction.

After the release of the detachable coil device in 1990, the decision regarding which technique, either endovascular or surgery, would bring better outcomes became more complex. The International Subarachnoid Aneurysm Trial ${ }^{16}$ in 2002 assessed the outcomes in patients with a ruptured aneurysm after the treatment either with endovascular coiling or surgical clipping. The trial showed better outcomes in terms of survival disability free after 1 year of treatment with endovascular treatment compared with neurosurgical treatment. Endovascular techniques in a posterior circulation aneurysm, mainly BA, have showed excellent results for small and narrow neck $(<4 \mathrm{~mm})$ aneurysms, ${ }^{5}$ but with wide neck aneurysms, the risks of coil prolapse ${ }^{4}$ and the incomplete occlusion of larger aneurysms increase. Different techniques to avoid coil prolapse have been reported such as the use of stent-assisted coiling. ${ }^{17}$ For a large BA aneurysm, the occlusion rates with endovascular treatment ranged between $7.6 \%$ and $67 \%{ }^{5}$

Posterior cerebral artery aneurysms have shown good results when treated with endovascular coiling. ${ }^{7}$ Berry aneurysms in nature were the ones with better outcomes, but giant or fusiform type aneurysms presented the same problem as wide neck BA aneurysms, mainly for incomplete occlusion. ${ }^{7}$ In these cases, the occlusion of the parent vessel is sometimes inevitable.

Superior cerebellar aneurysms have been treated mainly with endovascular coiling; the cases reported presented incomplete occlusion of the aneurysm in the majority. These results $^{12}$ can be explained when considering the aneurysm size-to-neck ratio and the inclusion of the parent artery origin into the aneurysm. In the first case the complete occlusion could lead to a prolapse of the coil to the parent vessel; in the second, the complete occlusion of the aneurysm would be impossible. ${ }^{12}$ Despite this, the endovascular treatment has shown positive long-term results.

In our study we wanted to investigate the feasibility of the endoscopic endonasal technique as a new window to treat this pathology. There are only nine cases ${ }^{18-26}$ reported in the literature that have used this technique for clipping aneurysms, and of these, only four cases are located in the posterior circulation ( $\mathbf{- T a b l e} \mathbf{1}$ ). Two cases presented aneurysms in the basilar trunk $\mathrm{k}^{18,19}$ and the other two in the right vertebral artery. $^{20,23}$ There are no cases reporting the use of this technique in the BA, posterior cerebral artery, or superior cerebellar artery. All the cases reported had successful results. Kassam et $\mathrm{al}^{23}$ presented a patient with a right vertebral artery aneurysm previously treated with endovascular coiling; in this case the need for a subsequent treatment performed by the author was due to the mass effect caused by the coiling mass responsible for new symptomatology. Fewer complications were seen, and all were successfully treated. As in our study this technique represented a direct route to treat posterior circulation aneurysms, also one to avoid brain retraction and extensive manipulation of the surrounding neurovascular structures. The surgical corridor was found to be adequate for visualization and for standard clip applicators to reach the three vessels studied; however, new instruments designed specifically for this purpose must be developed. We believe the expanded endoscopic approach is a potential alternative to treat posterior cerebral, superior cerebellar, and BA artery aneurysms.

\section{Conclusions}

The endoscopic endonasal transclival approach represents a direct anatomical route to the posterior cerebral artery, superior cerebellar artery origin, and basilar artery apex. We believe this approach is a feasible surgical corridor to treat aneurysms arising in these vessels through the use of standard vascular clip applicators without the need for excessive brain retraction and manipulation, thus adding an alternative treatment to the armamentarium of the skull base surgeon. 
312 A New Window for the Treatment of Aneurysms Lemos-Rodríguez et al.

Table 1 Cases reported in the literature of posterior circulation aneurysms treated with endoscopic endonasal approach

\begin{tabular}{|c|c|c|c|c|c|}
\hline Study & $\begin{array}{l}\text { Age, } \\
y / \text { Sex }\end{array}$ & $\begin{array}{l}\text { Initial symptoms/ } \\
\text { Findings }\end{array}$ & Location/size & Approach & Outcome \\
\hline $\begin{array}{l}\text { Kassam } \\
\text { et al }\end{array}$ & $51 / W$ & $\begin{array}{l}\text { Progressive clumsiness, } \\
\text { weakness, headache, } \\
\text { neck pain, sensory } \\
\text { alterations, } \\
\text { incoordination }\end{array}$ & $\begin{array}{l}\text { Partially thrombosed, } \\
\text { right vertebral artery } \\
\text { aneurysm, } 11 \mathrm{~mm}\end{array}$ & $\begin{array}{l}\text { First: Endovascular } \\
\text { therapy successful but } \\
\text { mass effect. } \\
\text { Second: Clipping and } \\
\text { aneurysmorrhaphy } \\
\text { through a transclival } \\
\text { transcondylar approach }\end{array}$ & $\begin{array}{l}\text { Excellent healing; im- } \\
\text { provement of preoper- } \\
\text { ative symptoms; no CSF } \\
\text { leakage }\end{array}$ \\
\hline $\begin{array}{l}\text { Eloy } \\
\text { et al }\end{array}$ & $28 / W$ & $\begin{array}{l}\text { HH grade III subarach- } \\
\text { noid hemorrhage }\end{array}$ & $\begin{array}{l}\text { Basilar trunk aneurysm, } \\
2.5 \times 2.2 \times 1.7 \mathrm{~mm}\end{array}$ & $\begin{array}{l}\text { Extended sublabial ap- } \\
\text { proach to the sella and } \\
\text { sphenoid }\end{array}$ & $\begin{array}{l}\text { Stable; presented vaso- } \\
\text { spasm that required } \\
\text { antihypertensive treat- } \\
\text { ment; it was necessary } \\
\text { to place a stent for per- } \\
\text { sistent fusiform dilation; } \\
\text { patient's poststenting } \\
\text { course was } \\
\text { unremarkable }\end{array}$ \\
\hline $\begin{array}{l}\text { Enseñat } \\
\text { et } \mathrm{al}^{20}\end{array}$ & $74 / \mathrm{W}$ & $\begin{array}{l}\text { Sudden onset of severe } \\
\text { headache, decreased } \\
\text { level of consciousness, } \\
\text { spatial and time dis- } \\
\text { orientation, subarach- } \\
\text { noid hemorrhage }\end{array}$ & $\begin{array}{l}\text { Right vertebral artery } \\
\text { saccular aneurysm, } \\
1.2 \mathrm{~mm}\end{array}$ & $\begin{array}{l}\text { Extended endonasal } \\
\text { transclival approach }\end{array}$ & $\begin{array}{l}\text { Postoperative course } \\
\text { uneventful; complete } \\
\text { obliteration and paten- } \\
\text { cy of vertebral and PICA } \\
\text { arteries } \\
\text { CSF leakage } 2 \text { wk after } \\
\text { surgery completely } \\
\text { repaired }\end{array}$ \\
\hline $\begin{array}{l}\text { Drazin } \\
\text { et } \mathrm{al}^{18}\end{array}$ & $59 / W$ & $\begin{array}{l}\text { Sudden onset of severe } \\
\text { headache; subarach- } \\
\text { noid hemorrhage HH } \\
\text { grade II }\end{array}$ & $\begin{array}{l}\text { Upper basilar artery } \\
\text { with an associated } \\
\text { feeding vessel to a small } \\
\text { cerebellar hemisphere } \\
\text { AVM }\end{array}$ & $\begin{array}{l}\text { First: Endovascular } \\
\text { treatment. Placement } \\
\text { of stent unsuccessful. } \\
\text { Second: Clipping trough } \\
\text { a suboccipital cranioto- } \\
\text { my unsuccessful. } \\
\text { Third: Extended endo- } \\
\text { nasal transclival } \\
\text { approach }\end{array}$ & $\begin{array}{l}\text { Partial occlusion of the } \\
\text { aneurysm and contin- } \\
\text { ued filling of the AVM } \\
\text { vessel. } \\
\text { Returned to the OR, for } \\
\text { reclipping that resulted } \\
\text { in immediate occlusion } \\
\text { and full recovery }\end{array}$ \\
\hline
\end{tabular}

Abbreviations: AVM, arteriovenous malformation; CSF, cerebrospinal fluid; $\mathrm{HH}$, Hunt and Hess (scale); OR, operating room; PICA, posteroinferior cerebellar artery.

Note

This article was presented in the poster session at the North American Skull Base Society Conference; February 20-22, 2015; Tampa, FL, USA.

\section{Acknowledgments}

We thank Matt Pillsbury, manager of the North Carolina Eye Bank Multidisciplinary Surgical Skills Laboratory, University of North Carolina at Chapel Hill.

\section{References}

1 Zanation AM, Carrau RL, Snyderman $\mathrm{CH}$, et al. Nasoseptal flap reconstruction of high flow intraoperative cerebral spinal fluid leaks during endoscopic skull base surgery. Am J Rhinol Allergy 2009;23(5):518-521

2 Patel MR, Taylor RJ, Hackman TG, et al. Beyond the nasoseptal flap: outcomes and pearls with secondary flaps in endoscopic endonasal skull base reconstruction. Laryngoscope 2014;124(4): 846-852
3 Hernesniemi J, Korja M. At the apex of cerebrovascular surgerybasilar tip aneurysms. World Neurosurg 2014;82(1-2):37-39

4 Marlin ES, Ikeda DS, Shaw A, Powers CJ, Sauvageau E. Endovascular treatment of basilar aneurysms. Neurosurg Clin N Am 2014;25(3): 485-495

5 Nanda A, Sonig A, Banerjee AD, Javalkar VK. Microsurgical management of basilar artery apex aneurysms: a single surgeon's experience from Louisiana State University, Shreveport. World Neurosurg 2014;82(1-2):118-129

6 Peerless SJ, Hernesniemi JA, Gutman FB, Drake CG. Early surgery for ruptured vertebrobasilar aneurysms. J Neurosurg 1994;80(4): 643-649

7 Ciceri EF, Klucznik RP, Grossman RG, Rose JE, Mawad ME. Aneurysms of the posterior cerebral artery: classification and endovascular treatment. AJNR Am J Neuroradiol 2001;22(1):27-34

8 Ferrante L, Acqui M, Trillò G, Lunardi P, Fortuna A. Aneurysms of the posterior cerebral artery: do they present specific characteristics? Acta Neurochir (Wien) 1996;138(7):840-852

9 Gerber CJ, Neil-Dwyer G. A review of the management of 15 cases of aneurysms of the posterior cerebral artery. Br J Neurosurg 1992; 6(6):521-527

10 Pia HW, Fontana H. Aneurysms of the posterior cerebral artery. Locations and clinical pictures. Acta Neurochir (Wien) 1977;38; (1-2):13-35 
11 International Study of Unruptured Intracranial Aneurysms Investigators. Unruptured intracranial aneurysms-risk of rupture and risks of surgical intervention. N Engl J Med 1998;339(24): 1725-1733Erratum in: N Engl J Med. 1999; 340:744

12 Haw C, Willinsky R, Agid R, TerBrugge K. The endovascular management of superior cerebellar artery aneurysms. Can J Neurol Sci 2004;31(1):53-57

13 Uda K, Murayama Y, Gobin YP, Duckwiler GR, Viñuela F. Endovascular treatment of basilar artery trunk aneurysms with Guglielmi detachable coils: clinical experience with 41 aneurysms in 39 patients. J Neurosurg 2001;95(4):624-632

14 Drake CG. The treatment of aneurysms of the posterior circulation. Clin Neurosurg 1979;26:96-144

15 Hsu FP, Clatterbuck RE, Spetzler RF. Orbitozygomatic approach to basilar apex aneurysms. Neurosurgery 2005;56(1, Suppl):172-177; discussion 172-177

16 Molyneux A, Kerr R, Stratton I, et al; International Subarachnoid Aneurysm Trial (ISAT) Collaborative Group. International Subarachnoid Aneurysm Trial (ISAT) of neurosurgical clipping versus endovascular coiling in 2143 patients with ruptured intracranial aneurysms: a randomized trial. J Stroke Cerebrovasc Dis 2002; 11(6):304-314

17 Fargen KM, Mocco J, Neal D, et al. A multicenter study of stentassisted coiling of cerebral aneurysms with a Y configuration. Neurosurgery 2013;73(3):466-472

18 Drazin D, Zhuang L, Schievink WI, Mamelak AN. Expanded endonasal approach for the clipping of a ruptured basilar aneurysm and feeding artery to a cerebellar arteriovenous malformation. J Clin Neurosci 2012;19(1):144-148

19 Eloy JA, Carai A, Patel AB, Genden EM, Bederson JB. Combined endoscope-assisted transclival clipping and endovascular stenting of a basilar trunk aneurysm: case report. Neurosurgery 2008; 62(3, Suppl 1):142-143; discussion 143-144

20 Enseñat J, Alobid I, de Notaris M, et al. Endoscopic endonasal clipping of a ruptured vertebral-posterior inferior cerebellar artery aneurysm: technical case report. Neurosurgery 2011;69 (1, Suppl Operative):E121-E127; discussion E127-E128

21 Froelich S, Cebula H, Debry C, Boyer P. Anterior communicating artery aneurysm clipped via an endoscopic endonasal approach: technical note. Neurosurgery 2011;68(2, Suppl Operative):310-316; discussion 315-316

22 Germanwala AV, Zanation AM. Endoscopic endonasal approach for clipping of ruptured and unruptured paraclinoid cerebral aneurysms: case report. Neurosurgery 2011;68(1, Suppl Operative):234-239; discussion 240

23 Kassam AB, Mintz AH, Gardner PA, Horowitz MB, Carrau RL, Snyderman $\mathrm{CH}$. The expanded endonasal approach for an endoscopic transnasal clipping and aneurysmorrhaphy of a large vertebral artery aneurysm: technical case report. Neurosurgery 2006;59(1, Suppl 1):E162-E165; discussion E162-E165

24 Kassam AB, Gardner PA, Mintz A, Snyderman CH, Carrau RL, Horowitz M. Endoscopic endonasal clipping of an unsecured superior hypophyseal artery aneurysm. Technical note. J Neurosurg 2007;107(5):1047-1052

25 Kassam AB, Thomas AJ, Zimmer LA, et al. Expanded endonasal approach: a fully endoscopic completely transnasal resection of a skull base arteriovenous malformation. Childs Nerv Syst 2007; 23(5):491-498

26 Kitano M, Taneda M. Extended transsphenoidal approach to anterior communicating artery aneurysm: aneurysm incidentally identified during macroadenoma resection: technical case report. Neurosurgery 2007;61(5, Suppl 2):E299-E300; discussion E300 